\title{
In Vitro Mid-Term Conservation of Acorus calamus L. via Cold Storage of Encapsulated Microrhizome
}

\author{
Afaque Quraishi $^{1 *}$, Snigdha Mehar ${ }^{1}$, Durga Sahu ${ }^{1}$, Shailesh Kumar Jadhav ${ }^{1}$. \\ ${ }^{1}$ Pandit Ravishankar Shukla University - School of Studies in Biotechnology, RAIPUR, India.
}

\begin{abstract}
In vitro rhizome production, encapsulation and cold storage of Acorus calamus were attempted for its propagation and 'true-to-type' conservation. Shoot cultures were initiated using underground rhizome buds, on 6-benzyladenine (BA) containing Murashige and Skoog (MS) medium. Maximum microrhizome production was observed in presence of $33.3 \mu \mathrm{M} \mathrm{BA}$, on modified MS medium containing $6 \%$ sucrose, $100 \mathrm{mg} / \mathrm{L}$ citric acid and $1 \mathrm{~g} / \mathrm{L}$ polyvinyl pyrrolidone-40. Synthetic seeds were produced from regenerated microtubers by encapsulation in calcium alginate beads. These synthetic seeds were stored in complete darkness at $10^{\circ} \mathrm{C}$ temperature for different durations for midterm conservation. After cold storage, synthetic seeds were re-cultured in vitro, $100 \%$ survival was recorded after the storage of 1, 3 or 6 months; and 80\% survival was observed after the storage of 12 months. The microrhizomes were produced roots in $4.9 \mu \mathrm{M}$ indole-3-butyric acid containing half strength MS medium. All the regenerated plantlets were successfully transferred to field after acclimatization. It is the first report on successful one year in vitro cold storage of A. calamus synthetic seeds.
\end{abstract}

Key words: Aromatic plant, Encapsulation, Sweet Flag, Synthetic seeds, Plant tissue culture

*Author for correspondence: drafaque13@gmail.com 


\section{INTRODUCTION}

Acorus calamus L. or Sweet Flag or Bach (family- Acoraceae) is a semi aquatic perennial herb distributed in Asia, North America and Europe. Plant may be indigenous to India, distributed in muddy places up to $1800 \mathrm{~m}$ height at 10 to $38^{\circ} \mathrm{C}$ temperature range ${ }^{1}$. Plant becomes endangered in many Indian states- Madhya Pradesh, Kerala, Andhra Pradesh and Chhattisgarh; also reported vulnerable in Tamil $\mathrm{Nadu}^{2}$, due to rigorous collections from natural habitat because of its economic and medicinal importance. It is a good source of $\beta$-asarone ${ }^{3}$. A. calamus is comprehensively used in the traditional medicines as sedative, anti-diarrheic, carminative, tonic, stimulant ${ }^{4}$. The essential oil extracted from rhizome of $A$. calamus used in perfumes and beverages ${ }^{5}$. Seed production is scanty in this herb; hence, rhizomes are mainly used as propagule for its traditional cultivation, which has a slow rate of propagation ${ }^{6}$. Therefore, in vitro techniques may provide faster mass propagation for production of its disease free quality planting material as well as means of germplasm conservation. Reports are there on micropropagation of $A$. calamus $^{7,8,9,10}$. Another technique namely, in vitro storage organ production has many advantages over in vitro plantlet regeneration; for example microtubers/rhizomes can be easily acclimatized, easier to handle, storage and exchange of germplasm, etc. Thus, selected clones can be maintained safely by tissue culture technique under disease and pest free environment. However, under the normal culture conditions, continuous growth of cultures is there induced by exogenous plant growth regulators and cultures are also subjected to frequent subcultures for long durations; may induce off types via somaclonal variations ${ }^{11,12,13}$. Therefore, growth of in vitro cultures must be checked for storage of germplasm to overcome the risk of off type production and it is economic too in comparison to maintain fast growing cultures ${ }^{14}$. Long term in vitro storage is carried out in liquid nitrogen that is a costly and highly technical method. In vitro cold storage technique is used for mid-term conservation has many plus points i.e., simple, economic, disease free with lower requirement of manpower and space. It is also suitable for commercial micropropagation units; as in vitro cold stored material can be multiplied according to demand. In vitro microrhizome production of A. calamus is reported by Devi et al. ${ }^{6}$. Encapsulation of microrhizomes (synthetic seeds) of this species and its in vitro conservation by synthetic seeds via storage in dark at low temperature is reported firstly here.

\section{MATERIAL AND METHODS}

\section{Explant Establishment}

Mother plants of A. calamus were collected from Chhattisgarh State Forest Departmental Nursery, Raipur (India). The underground rhizome segments with shoot buds were used as explants to start in vitro culture. The rhizomes were washed thoroughly in running tap water to remove soil and then divided into approximately $2 \mathrm{~cm}$ pieces each. Leaves and roots were also removed from explants. Then the explants were treated with $1 \%$ Tween-80 for 15 minutes. Next step was carried out under laminar airflow hood; explants were dipped in fungicide solution $(0.1 \%$ Carbendazim and $0.25 \%$ Mancozeb) for 30 minutes, followed by rinsing with sterile distilled water for $3-4$ times. Now the explants were quickly dipped in $70 \%$ ethanol and then finally were surface disinfested with $0.2 \%(w / v)$ aqueous mercuric chloride for 20 minutes and were rinsed $4-5$ times with sterile distilled water. Again the explants were cut to final size approximately $1 \mathrm{~cm}$ long and then were transferred aseptically on to culture establishment medium. 
In vitro cold storage of Acorus calamus

Murashige and Skoog (MS) medium ${ }^{15}$ supplemented with 3\% sucrose and different concentration of 6-benzyladenine (BA) was used as culture medium. The media were adjusted to $\mathrm{pH} 5.7$ with $1 \mathrm{~N} \mathrm{NaOH}$ and sterilized by autoclaving for $20 \mathrm{~min}$ at $1.05 \mathrm{~kg} / \mathrm{cm}^{2}$ pressure at $121^{\circ} \mathrm{C}$. The inoculation were carried out and the cultures was incubated at $25^{\circ} \mathrm{C} \pm 2$ under $16 / 8$ (day/night) photoperiod with $40 \mu \mathrm{mol} \mathrm{m} \mathrm{m}^{-2} \mathrm{~s}^{-1}$ light intensity provided through white cool fluorescent tubes. Explant establishment and rooting experiments were carried out in $25 \times 150 \mathrm{~mm}$ glass culture tubes containing $15 \mathrm{ml}$ medium each, and $250 \mathrm{ml}$ conical flasks containing $50 \mathrm{ml}$ medium each were used for microrhizome production studies, respectively. The bud break percentage, number and length of shoots per explant were recorded after the 30 days of culture.

Microrhizome Induction

The in vitro elongated shoots were further used for protocol standardization of microrhizome induction. Two different levels of sucrose viz 6 and $9 \%$ were supplemented in MS medium. Along with sucrose three different concentrations of BA were also incorporated in the media. Activated charcoal $(0.1 \%)$ was also evaluated for microrhizome induction along with 6 and $9 \%$ of sucrose supplemented medium. MS medium containing 6\% sucrose without any PGR serves as control for this experiment. The number and length of microrhizomes produced from each culture were recorded after 30 days of culture.

\section{Microrhizome Production}

After 30 days, the shoots elongated from the explants were excised; leaves were trimmed and then used for microrhizome production. MS medium with best responded sucrose level was used for microrhizome production. This microrhizome production medium was also contained $100 \mathrm{mg} / \mathrm{L}$ citric acid and $1 \mathrm{~g} / \mathrm{L}$ polyvinyl pyrrolidone-40 (PVP-40). The different concentrations of BA were also incorporated in to this modified MS medium for study the effect of microrhizome production. The number and length of microrhizomes produced from each culture were recorded after 30 days of culture.

\section{Encapsulation and Cold Storage}

For synthetic seed production, in vitro produced microrhizomes were encapsulated into calcium alginate beads. The microrhizomes were suspended in sterilized $3 \%$ sodium alginate solution in $1 / 2$ strength of MS medium; and were dispensed dropwise into sterilized $3 \%$ calcium chloride solution to trap in calcium alginate gel. These encapsulated microrhizomes were washed with sterile distilled water and were sealed in petri-plates. Further, these synthetic seeds were stored at $10^{\circ} \mathrm{C}$ in complete darkness for different durations i.e., 1, 3, 6 or 12 months. After different time periods, survival percentage of the cold stored synthetic seeds were analyzed by reculture them on to the microrhizome production medium under the normal culture conditions.

\section{Rooting and Acclimatization}

In vitro grown microrhizomes were subjected to rooting in the presence of $4.9 \mu \mathrm{M}$ indole-3-butyric acid (IBA) in $1 / 2$ strength MS medium. For acclimatization, plantlets with well developed roots were removed from vessels, washed thoroughly in tap water to remove the nutrient medium and then dipped in fungicide solution $(0.1 \%$ Carbendazim and $0.25 \%$ Mancozeb) for 30 minutes. The plantlets were then transplanted to pots containing coco-pit. These pots were placed at $30^{\circ} \mathrm{C} \pm 2$ and $90 \%$ relative humidity $(\mathrm{RH})$ for one month. For secondary hardening, $\mathrm{RH}$ is gradually reduced in next two months; finally transferred to the field. 


\section{Data Analysis}

All the experiments were of completely randomized design; contained ten replicates in each treatment, and each experiment was repeated thrice (total thirty replicates). The data were analyzed by the analysis of variance (ANOVA), means were separated by Duncan's Multiple Range Test (DMRT), at 5\% level; using SPSS-10 software ${ }^{16}$.

\section{RESULTS AND DISCUSSIONS}

\section{Explant Establishment}

Underground rhizome bud explants of A. calamus were exhibited $100 \%$ bud break in growth regulator free basal MS medium (Table 1). However, shoot number as well as shoot length were highly influenced by concentration of BA, as probability $(p)$ of ANOVA was $<0.0001$. Highest shoot number and elongation were recorded in the presence of $35.52 \mu \mathrm{M} \mathrm{BA}$, as both the values were ranked ' $\mathrm{a}$ ' by DMRT in comparison to other concentrations including control. Beneficial effect of BA on explant establishment of A. calamus was also observed previously ${ }^{8}$.

Table 1 - Effect of BA level on shoot initiation of Acorus calamus nodal explants on MS medium. Observations were recorded after the 30 days of culture.

\begin{tabular}{|c|c|c|c|}
\hline$(\mu \mathrm{M})$ & $\begin{array}{l}\text { Bud } \\
\text { Break } \\
(\%)\end{array}$ & $\begin{array}{l}\text { Shoot } \\
\text { Number } \\
(\text { Mean } \pm \text { SE) }\end{array}$ & $\begin{array}{l}\text { Shoot } \\
\text { Length } \\
\text { (cm) } \\
(\text { Mean } \pm \text { SE) }\end{array}$ \\
\hline 0 & 100 & $1.0 \pm 0^{\mathbf{c}}$ & $0.75 \pm 0.04^{\mathbf{b}}$ \\
\hline 4.44 & 100 & $1.0 \pm 0^{\mathbf{c}}$ & $0.75 \pm 0.03^{\mathbf{b}}$ \\
\hline 8.88 & 100 & $1.25 \pm 0.08^{\mathbf{b}}$ & $0.50 \pm 0.01^{\mathrm{c}}$ \\
\hline 17.76 & 100 & $1.40 \pm 0.09^{\mathbf{b}}$ & $0.58 \pm 0.03^{\mathrm{c}}$ \\
\hline 35.52 & 100 & $1.50 \pm 0.09^{\mathrm{a}}$ & $1.15 \pm 0.04^{\mathrm{a}}$ \\
\hline
\end{tabular}

Each experiment consisted of 10 replicates and each experiment was repeated three times. Similar letters followed by mean values do not differ significantly at $5 \%$ level, by DMRT.

ANOVA:

$\begin{array}{llll}\text { ANOVA: } & \boldsymbol{d} \boldsymbol{f} & \boldsymbol{F} & \boldsymbol{p} \\ \text { Shoot Number: } & 4 & 11.248 & <0.0001 \\ \text { Shoot Length: } & 4 & 47.988 & <0.0001\end{array}$

\section{Microrhizome Induction}

Microrhizome induction was more influenced by enhanced level of sucrose along with combination of PGR (Table 2). Both the sucrose level (6 and 9\%) in combination with slightly increased concentration of BA was found favorable for microrhizome induction. However, $6 \%$ sucrose level induced more numbers of in vitro rhizomes instead of $9 \%$ level. Moreover, black leaching was observed in all the rhizome inducing cultures. Thus, for microrhizome production $6 \%$ sucrose level was opted with various concentration of BA. In previous report also, $6 \%$ sucrose level was found suitable for induction of microrhizome in the same plant ${ }^{6}$. 
In vitro cold storage of Acorus calamus

Table 2 - Effects of sucrose level in combination with different concentration of BA on microrhizome induction of Acorus calamus on MS medium. Observations were recorded after the 30 days of culture.

\begin{tabular}{|c|c|c|c|c|c|}
\hline$(\mu \mathbf{M})$ & Sucrose & $\begin{array}{l}\text { Activated } \\
\text { Charcoal } \\
(\%)\end{array}$ & $\begin{array}{l}\text { Rhizome } \\
\text { Induction } \\
(\%)\end{array}$ & $\begin{array}{l}\text { Rhizome } \\
\text { Number } \\
\text { (Mean } \pm \text { SE) }\end{array}$ & $\begin{array}{l}\text { Rhizome } \\
\text { Length } \\
\text { (cm) } \\
(\text { Mean } \pm \text { SE) }\end{array}$ \\
\hline 0 & 6 & - & 100 & $1.5 \pm 0.1^{b c}$ & $2.5 \pm 0.2^{\mathbf{b}}$ \\
\hline 4.44 & 6 & - & 100 & $2.2 \pm 0.3^{\mathrm{a}}$ & $2.5 \pm 0.2^{b}$ \\
\hline 17.76 & 6 & - & 100 & $1.8 \pm 0.2^{\mathbf{a b}}$ & $3.2 \pm 0.2^{\mathbf{a b}}$ \\
\hline 35.52 & 6 & - & 100 & $1.4 \pm 0.1^{\mathrm{c}}$ & $2.8 \pm 0.2^{\mathrm{c}}$ \\
\hline 35.52 & 9 & - & 100 & $1.3 \pm 0.1^{\mathrm{c}}$ & $1.8 \pm 0.3^{c}$ \\
\hline 35.52 & 6 & 0.1 & 100 & $1.2 \pm 0.1^{\mathrm{c}}$ & $1.4 \pm 0.1^{\mathrm{c}}$ \\
\hline 35.52 & 9 & 0.1 & 100 & $1.3 \pm 0.1^{\mathrm{c}}$ & $2.8 \pm 0.2^{\mathrm{c}}$ \\
\hline
\end{tabular}

Each experiment consisted of 10 replicates and each experiment was repeated three times. Similar letters followed by mean values do not differ significantly at $5 \%$ level, by DMRT.

ANOVA:

Rhizome Number:

Rhizome Length:

$\begin{array}{lll}\boldsymbol{d} \boldsymbol{f} & \boldsymbol{F} & \boldsymbol{p} \\ 6 & 6.07 & <0.0001 \\ 6 & 13.8 & <0.0001\end{array}$

\section{Microrhizome Production}

For microrhizome production, the shoots which were elongated from the explants were removed from vessels aseptically after one month of culture and each shoot was divided into nodes and cultured onto microrhizome production medium. At induction stage slight blackening and phenolic leaching were observed in cultures that may inversely affect the number of microrhizome (Table 2). To overcome this problem, citric acid (antioxidant) and PVP-40 (absorbent) were also incorporated into the production medium. The problem of blackening and leaching in Lagerstroemia parviflora cultures were also circumvent by the similar strategy ${ }^{17}$. In vitro microrhizome production (number and length) was also influenced by BA level in the medium as $p$ of ANOVA was highly significant $(<0.0001)$ (Fig. 1 and Fig. 2). Maximum microrhizomes were produced in the presence of $33.3 \mu \mathrm{M} \mathrm{BA}$, as both microrhizome number and length were ranked ' $a$ ' by DMRT. Higher level of sucrose in culture medium facilitates higher carbon energy to induce formation of storage organs in vitro ${ }^{18,19}$. Presence of cytokinin in culture medium with high sucrose level positively influenced microrhizome formation, probably because microrhizome is a modified shoot. Therefore, the best microrhizome formation in high BA and high sucrose containing medium was also reported in Curcuma aromatica ${ }^{19}$, Curcuma amada $^{20}$, Kaempferia galanga ${ }^{21}$. 


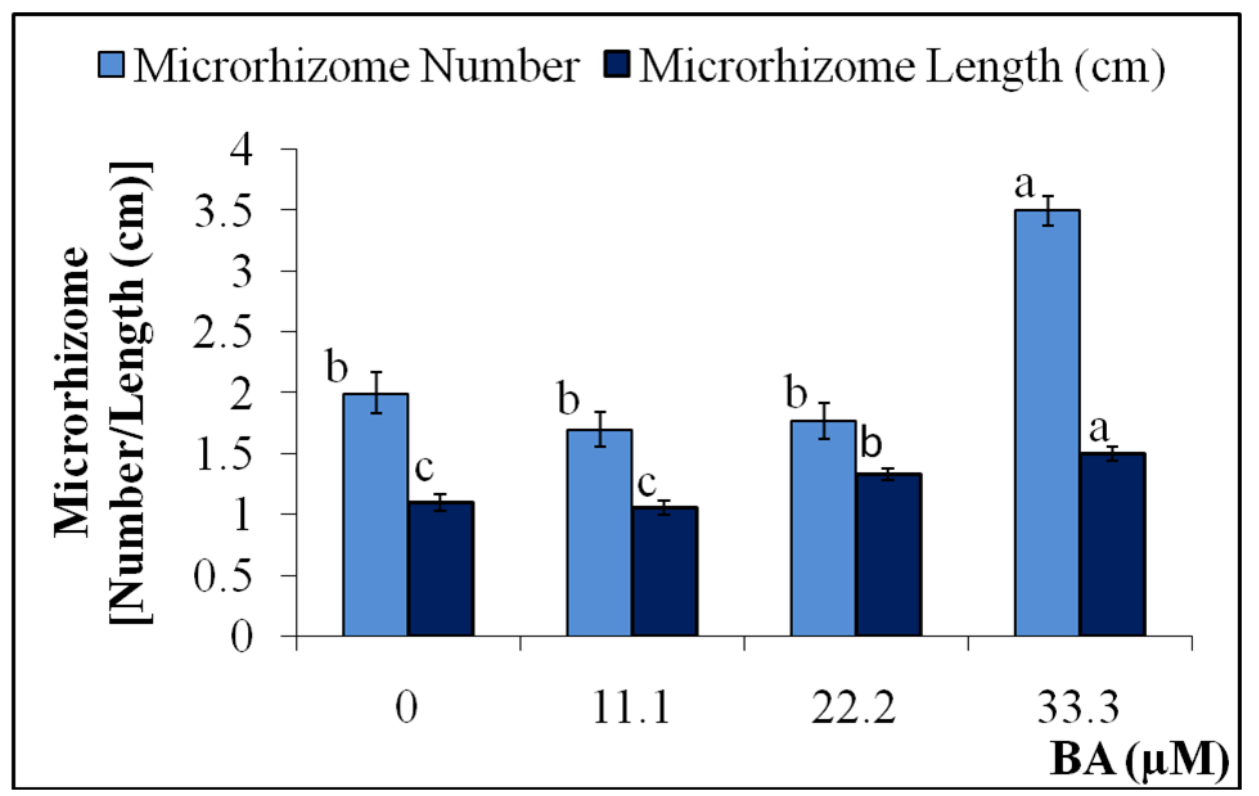

Figure 1 - Effect of BA concentration on in vitro microrhizome formation of Acorus calamus in MS medium supplemented with $60 \mathrm{~g} \mathrm{~L}^{-1}$ sucrose $(6 \%), 100 \mathrm{mg} \mathrm{L}^{-1}$ citric acid and $1 \mathrm{~g} \mathrm{~L}^{-1} \mathrm{PVP}-40$. Observations were recorded after the 30 days of culture.

Each experiment consisted of 10 replicates and each experiment was repeated three times. Similar letters on mean values do not differ significantly at $5 \%$ level, by DMRT.

ANOVA:

Shoot number:

Shoot Length:

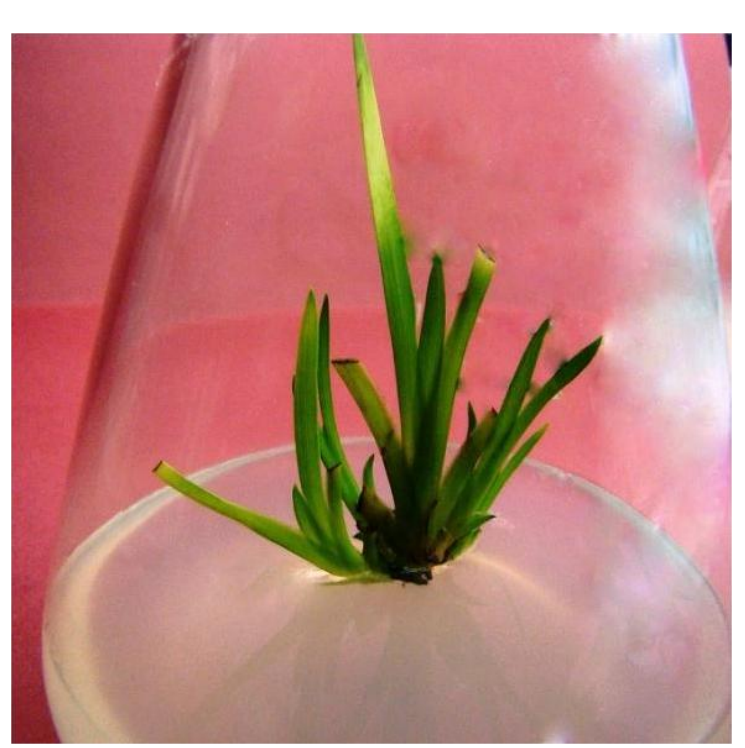

Figure 2 - In vitro microrhizome production of Acorus calamus, on MS medium supplemented with $33.3 \mu \mathrm{M}$ $\mathrm{BA}, 60 \mathrm{~g} \mathrm{~L}^{-1}$ sucrose, $100 \mathrm{mg} \mathrm{L}^{-1}$ citric acid and $1 \mathrm{~g} \mathrm{~L}^{-1}$ PVP-40.

\section{Encapsulation and Cold Storage}

The regenerated microrhizomes of $A$. calamus were encapsulated in calcium alginate gel using sodium alginate and calcium chloride solutions to produce synthetic seeds (Fig. 3A). Synthetic seeds were also produced by encapsulation of in vitro grown vegetative propagules in calcium alginate beads in many species i.e., Acacia hybrid $^{22}$, Cassia angustifolia ${ }^{23}$, etc. They can be used like real seeds for transport, storage and plant production. Therefore, synthetic seeds of A. calamus were further tested for cold storage for mid-term conservation. For the purpose, they were 
In vitro cold storage of Acorus calamus

aseptically sealed in petri-dishes and were kept at $10^{\circ} \mathrm{C}$ in complete darkness for different durations. Up to 6 months, the cold stored synthetic seeds were showed $100 \%$ survival when re-cultured onto the microrhizome production medium (Fig. 3B and Fig. 4). After the one year of cold storage, $80 \%$ synthetic seeds were survived. Thus, encapsulated microtubers as synthetic seeds were stored for one year without any subculture in economic manner. Although the microrhizome cold storage of $A$. calamus has not been reported previously, but the cold storage of in vitro raised storage organs has been reported in other plant species. In Zingiber microrhizomes, $50 \%$ survival was recorded up to 14 months under $16 \mathrm{~h}$ and $24 \mathrm{~h}$ light in normal culture condition; and only $20 \%$ survival under dark incubation ${ }^{24}$. Potato microtubers were stored in dark at $4^{0} \mathrm{C}$ for 12 to 15 months ${ }^{25}$. Nonetheless, in vitro culture storage provides conservation and safe exchanges of germplasm that can be bulked up again whenever required ${ }^{26}$.

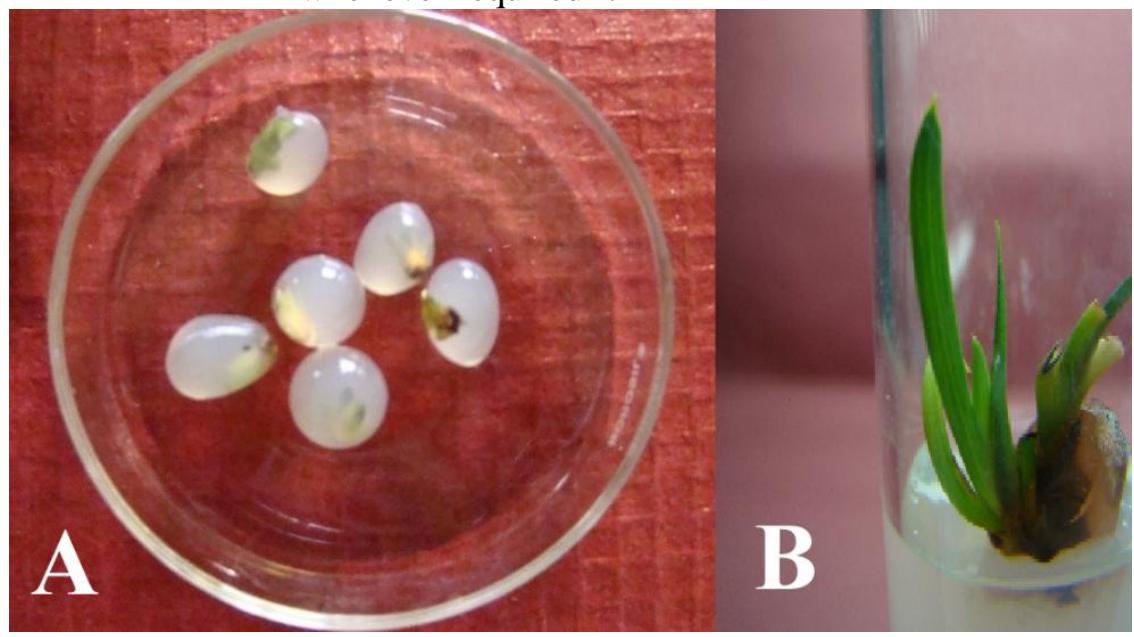

Figure 3 - In vitro cold storage of Acorus calamus. A: Synthetic seeds produced by microrhizome encapsulation in calcium alginate beads. B: Re-growth of synthetic seed after one year of storage at $10^{\circ} \mathrm{C}$ in dark.

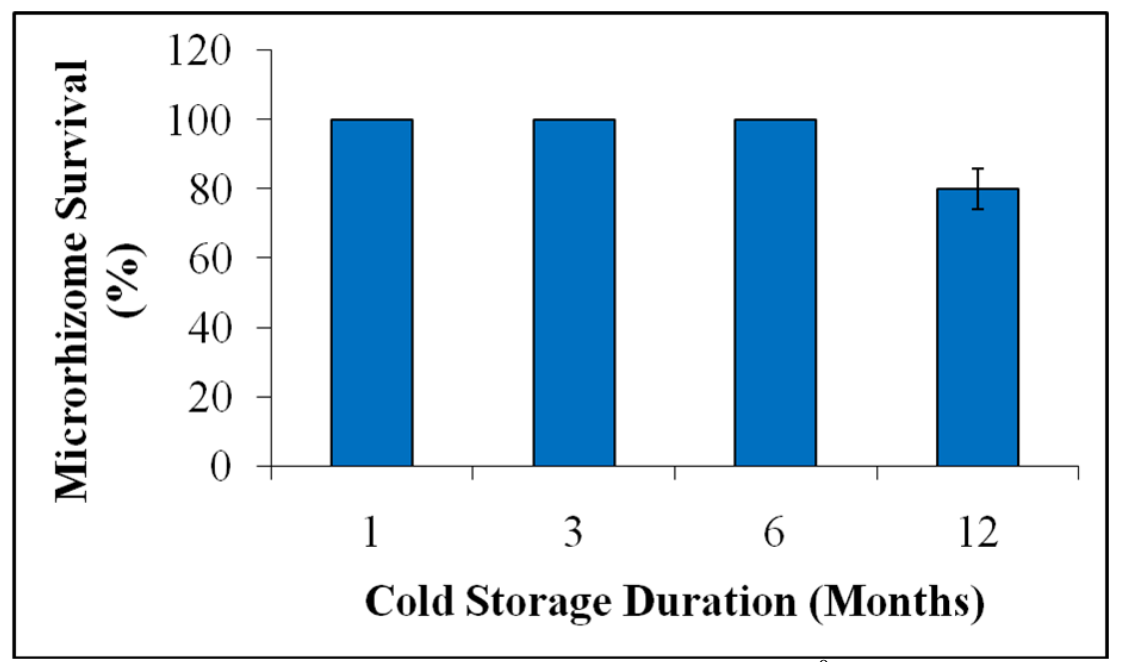

Figure 4 - Survival percentage of in vitro cold stored $\left(10^{0} \mathrm{C}\right.$ in dark) synthetic seeds of Acours calamus, after the re-culture. Each experiment consisted of 10 replicates and each experiment was repeated three times.

\section{Rooting and Acclimatization}

Each microrhizome was aseptically transferred to rooting medium for complete plantlet formation. These microrhizomes were easily rooted in presence of an auxin4.9 $\mu \mathrm{M}$ IBA in half strength MS medium. All the regenerated plantlets were 
survived after one month of acclimatization in greenhouse. Similar, high rate of survival in A. calamus microrhizomes after acclimatization was also recorded previously ${ }^{6}$.

\section{CONCLUSION}

Thus, the developed protocol facilitates simple in vitro technique for synthetic seed production by encapsulation of microrhizomes and conservation via these synthetic seeds in complete dark at $10^{\circ} \mathrm{C}$ up to one year; for this economically important medicinal and aromatic plant- A. calamus.

\section{ACKNOWLEDGEMENTS}

Authors are thankful to Head of School of Studies in Biotechnology, Pt. Ravishankar Shukla University, Raipur (India) for providing laboratory facilities and support.

\section{REFERENCES}

1. Sharma V, Singh I, Chaudhary P. Acorus calamus (The Healing Plant): a review on its medicinal potential, micropropagation and conservation. Nat Prod Res. 2014; DOI: 10.1080/14786419.2014.915827

2. FRLHT (Foundation for Revitalisation of Local Health Traditions), Bangalore, India. Updated in $4^{\text {th }}$ May 2016. Accessed in $13^{\text {th }}$ May 2016. Available from http://envis.frlht.org/medicinal-plants-conservation-concern-species.php

3. Mazza G. Gas chromatographic and mass spectrometric studies of the constituents of the rhizome of calamus: the volatile constituents of the essential oil. J Chromatogr A. 1985; 328:179-194.

4. McGaw LJ, Jager AK, Staden J. Isolation of $\beta$-asarone, an antibacterial and anti-helminthic compound from Acorus calamus in South Africa. S Afr J Bot. 2002; 61:31-35.

5. Motley TJ. The ethnobotany of sweet flag, Acorus Calamus (Araceae). Econ Bot. 1994; 48:397-412.

6. Devi NS, Kishir R, Sharma GJ. Microrhizome induction in Acorus calamus Linn. - An important medicinal and aromatic plant. Hortic Environ Biote. 2012; 53(5):410-414.

7. Harikrishnan KN, Hariharan M. In vitro propagation of sweet flag (Acorus calamus L.) - a medicinal plant. In: Kishore PBK, Editor. Plant Tissue Culture and Biotechnology: Emerging Trends Hyderabad (India): Universities Press; 1999. p. 220-223.

8. Rani AS, Subhadra VV, Reddy VD. In vitro propagation of Acorus calamus Linn. - A medicinal plant. Indian J Exp Biol. 2000; 38:730-732.

9. Anu A, Babu KN, John CZ, Peter KV. In vitro clonal multiplication of Acorus calamus. J Plant Biochem Biot. 2001; 10:53-55.

10. Sandhyarani N, Kishor R, Sharma GJ. Clonal propagation of triploid Acorus calamus Linn. using dual-phase culture system. J Crop Sci Biotech. 2011; 14(3):213-217.

11. Bairu MW, Aremu AO, Staden JV. Somaclonal variation in plants: causes and detection methods. Plant Growth Regul. 2011; 63:147-173.

12. Hrahsel L, Basu A, Sahoo L, Thangjam R. In vitro propagation and assessment of the genetic fidelity of Musa acuminata (AAA) cv. Vaibalhla derived from immature male flowers. Appl Biochem Biotech. 2014; 172:1530-1539.

13. Devi SP, Kumaria S, Rao SR, Tandon P. Single primer amplification reaction (SPAR) methods reveal subsequent increase in genetic variations in micropropagated plants of Nepenthes khasiana Hook. f. maintained for three consecutive regenerations. Gene 2014; 538:23-29

14. Chauhan R, Keshavkant S, Jadhav SK, Quraishi Afaque. In vitro slow-growth storage of Chlorophytum borivilianum Sant. et Fernand: a critically endangered herb. In Vitro Cell Dev-Pl. 2016; 52:315-321.

15. Murashige T, Skoog F. A revised medium for rapid growth and bioassay with tobacco tissue culture. Physiol Plant. 1962; 15:473-497. 
In vitro cold storage of Acorus calamus

16. SPSS, Inc. SPSS 10.0 syntax reference guide. Chicago, IL; 1999.

17. Quraishi A, Koche V, Mishra SK. Micropropagation of Lagerstroemia parviflora through axillary bud culture. Silvae Genet. 1997; 46(4):242-245.

18. Tyagi RK, Bhat SR, Chandel KPS. In vitro conservation strategies for spices crop germplasm Zingiber, Curcuma and Piper species. In: Mathew NM, Kuruvila JC, Editors. Developments in plantation crop research. India: Rubber Research Institute of India; 1998. p. 77-82.

19. Nayak S. In vitro multiplication and microrhizome induction in Curcuma aromatic Salisb. Plant Growth Regul. 2000; 32:41-47.

20. Nayak S. High frequency in vitro production of microrhizomes of Curcuma amada. Indian J Exp Biol. 2002; 40:230-232.

21. Chirangini P, Sinha SK, Sharma GJ. In vitro propagation and microrhizome induction in Kaempferia galanga Linn. and K. rotunda Linn. Indian J Biotechnol. 2005; 4:404-408.

22. Nor Asmah H, Nor Hasnida H, Noraliza A, Nashatul Zaimah NA, Nadiah Salmi N. In vitro propagation of Acacia hybrid through alginate-encapsulated shoots and axillary buds. Afr $J$ Biotechnol. 2012; 11(65):12814-12817.

23. Bukhari NAW, Siddique I, Perveen K, Siddiqui I, Alwahibi MS. Synthetic seed production and physio-biochemical studies in Cassia angustifolia Vahl. - a medicinal plant. Acta Biol Hung. 2014; 65(3):355-367.

24. Tyagi RK, Anuradha A, Yusuf A. Conservation of Zingiber germplasm through in vitro rhizome formation. Sci Hortic-Amsterdam. 2006; 108:210-219.

25. Mix-Wagner G. The conservation of potato cultivars. Potato Res. 1999; 42:427-436.

26. Nayak S, Naik PK. Factors effecting in vitro microrhizome formation and growth in Curcuma longa L. and improved field performance of micropropagated plants. ScienceAsia. 2006; 32:31-37. 